\title{
Colonoscopy in Rural Communities: Can Family Physicians Perform the Procedure with Safe and Efficacious Results?
}

Jeffrey K. Edwards, MD, and Thomas E. Norris, MD

Background: Colonoscopy is becoming increasingly necessary for many patients in screening, diagnosing, and treating colorectal problems. Because the majority of rural doctors are family physicians, providing colonoscopy for the enlarging group of patients with valid indications in rural areas is difficult, unless rural family physicians perform the procedure. Subspecialists in academic settings have been responsible for most of the previously reported studies regarding colonoscopy. We have studied the safety and efficacy of the procedure when performed by rural family physicians.

Methods: A total of 200 sequential colonoscopies performed by family physicians in a rural setting were prospectively collected. Outcomes were measured based on current recommendations and benchmarks, including rate of reaching the cecum, time to reach the cecum, time to completion of the study, pathologic lesions found, and complications.

Results: The rate of reaching the cecum was $96.5 \%$, and the average time to the cecum was 15.9 minutes. The average time to study completion was 34.4 minutes. The rate of neoplastic polyps and cancer found was $22.5 \%$ and $2.5 \%$, respectively. There were no serious complications.

Conclusions: Adequately trained family physicians can provide safe and technically competent colonoscopy in a rural setting. Their results compare favorably to the currently reported comparative benchmarks from other endoscopists. (J Am Board Fam Pract 2004;17:353-8.)

Colon cancer is a preventable but potentially fatal disease. In the last 2 decades, research has established that most colon cancers arise from neoplastic polyps within the colon. If these polyps are found early and removed, colon cancer can be prevented. There is currently a growing national movement to screen patients at risk for colon cancer, with a consequential growing need for surveillance of patients with a history of polyps or colon cancer. Many physicians and patients prefer colonoscopy as the "reference standard" screening study for colon polyps and cancer as well as polyp surveillance. Unfortunately, there is a lack of qualified colonoscopists in rural areas. The majority of rural doctors are family physicians. If colonoscopies are to be offered widely in rural areas, family physicians will need to perform them.

Submitted, revised, 6 April 2004.

From the St. Mary's Hospital, Cottonwood, ID (JKE); and the School of Medicine, University of Washington, Seattle (TEN). Address correspondence to Thomas E. Norris, MD, School of Medicine, University of Washington, Seattle, WA 98195-6340 (e-mail: tnorris@u.washington. edu).
We present 200 prospectively collected sequential colonoscopy cases performed by rural family physicians, and we provide a comparison with regard to the quality and safety of the procedure as found by a current review of the literature. ${ }^{1-23} \mathrm{It}$ has been reported that a competent colonoscopist can reach the cecum more than $90 \%$ of the time, ${ }^{1,3-6,10-12,15-18,21,22}$ in a reasonable amount of time. ${ }^{1,5,6,8,16,18,20-22}$ Colonoscopy can be completed with a minimal amount of risk to the patient $\mathrm{t}^{3,6,7,10-12,16,18,20,23}$ and with a satisfactory rate of detection of pathologic lesions. ${ }^{3,8,10,11,12,16,24}$

\section{Methods}

Data were collected at the time of the procedure on 200 consecutive colonoscopies performed at St. Mary's Hospital in Cottonwood, Idaho. St. Mary's Hospital is a rural, 14-bed health care facility in north central Idaho that serves the largest county, in terms of area, in the state. This service area includes a patient population of 12,000 to 15,000 people. All colonoscopies completed by family physicians at St. Mary's Hospital over a 2-year period from December 2000 through January 2002 were included in the study. These cases included both 


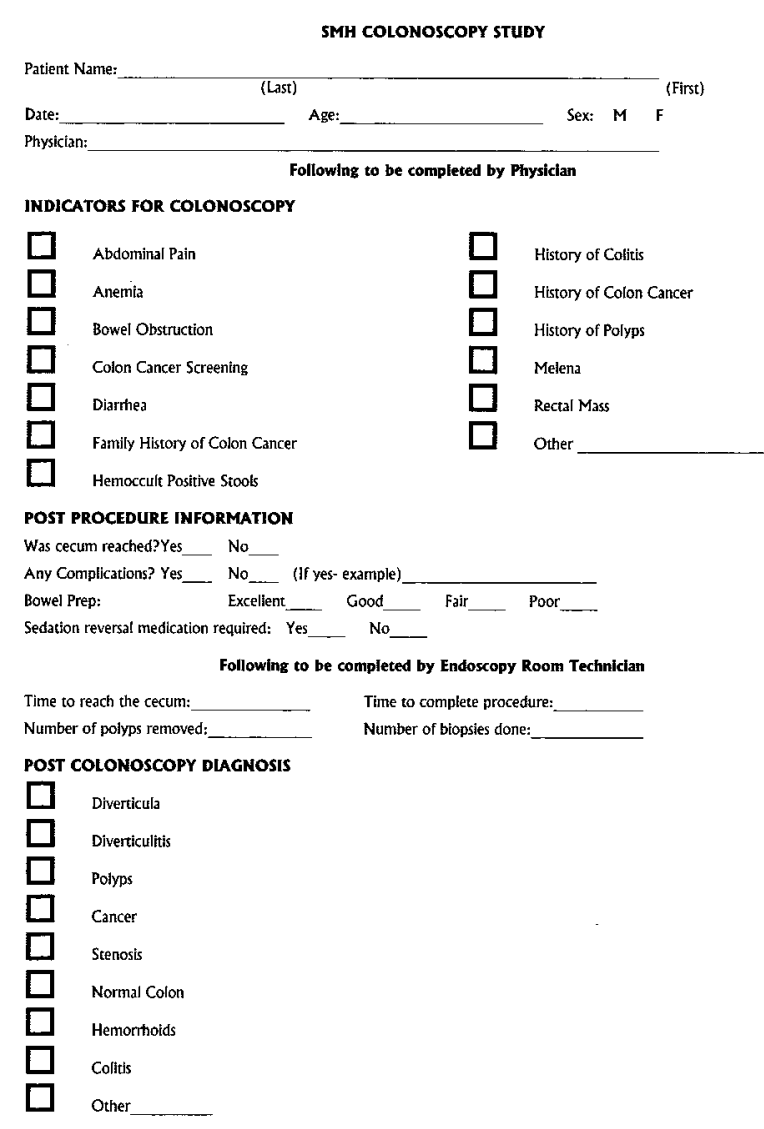

Figure 1. Standardized data collection form.

inpatient (urgent) and outpatient (nonurgent) study participants.

The data were collected prospectively during the study period. A standardized data collection form was completed at the time of each procedure. Figure 1 shows the standardized form used to collect colonoscopy data. The physician completed this form immediately after the colonoscopy (before pathology reports were available), and endoscopy room staff recorded procedure times. Study patients were then called 1 to 3 days after the procedure to review for any problems unless they were inpatients already.

Pathology reports were collected for all procedures in which tissue specimens were obtained. Only in situations in which the pathologist confirmed biopsy results were polyps of neoplastic origin reported (adenomatous, tubular, or villous) or the case designated as colon cancer. Pathology reports of hyperplastic polyps and other nonmalignant findings were excluded from the analysis. $\mathrm{Mi}$ crosoft Access (Microsoft Corp., Redmond, WA) was the database used for storage and analysis of the data. Analysis of the data included only the calculation of totals (sums) and percentages, using all the cases included in the study. No statistical calculations were required or performed. Data were analyzed by category, including demographics, procedure indication, time to cecum, time to completion of colonoscopy, complications, and findings. After data collection, outcome results from this descriptive study were compared with others reported in the literature.

All procedures were completed by 1 of 4 rural family physicians. The 3 younger physicians had been trained to do colonoscopy in their residencies. A younger physician proctored the oldest physician (who had been doing flexible sigmoidoscopy) until he was proficient with colonoscopy.

The colonoscopies were all performed in a dedicated hospital endoscopy room at St. Mary's Hospital. In all cases presented in this report, Certified Registered Nurse Anesthetists provided intravenous conscious sedation. It is noted that in other settings, other trained personnel could provide this service. Intravenous sedation used included a combination of midazolam, fentanyl, and propofol. Continuous cardiorespiratory monitoring was done during each procedure. An Olympus video colonoscope, model CFQ140L, was used for all procedures.

\section{Results}

Two hundred consecutive sequential colonoscopy procedures were performed over a 2-year period at St. Mary's Hospital from December 2000 through January 2002 by 4 family physicians. Of the 200 patients, 91 were women and 109 were men. The age range of patients was from 16 to 90 years, with an average patient age of 62 years. The number of colonoscopies completed per physician varied from 23 to 108 . Table 1 shows the estimated number of

Table 1. Estimated Number of Colonoscopies and the Total Years Physicians Had Been Performing Colonoscopy before Beginning the Study

\begin{tabular}{lcc}
\hline Physician & $\begin{array}{c}\text { Number } \\
\text { of Cases }\end{array}$ & $\begin{array}{c}\text { Years } \\
\text { Performing Procedure }\end{array}$ \\
\hline A & $<50$ & 3 \\
B & 50 to 100 & 8 \\
C & 100 to 200 & 12 \\
D & $>500$ & 15 \\
\hline
\end{tabular}


Table 2. Most Common Indications for 200 Colonoscopies (Some Cases Had Multiple Indications)

\begin{tabular}{lcc}
\hline Indication & $\begin{array}{c}\text { Number } \\
\text { of Cases }\end{array}$ & $\begin{array}{c}\text { Percentage } \\
\text { of Cases }\end{array}$ \\
\hline Rectal bleeding & 52 & 26 \\
Hx of polyps & 49 & 25 \\
FHx of colon cancer & 44 & 22 \\
Stools positive for FOBT & 35 & 18 \\
\hline
\end{tabular}

Hx, history; FHx, family history; FOBT, fecal occult blood testing.

colonoscopies and years of experience performing colonoscopy by a physician before beginning the study. The most frequent indication for colonoscopy was rectal bleeding. Some patients had multiple indications for colonoscopy, whereas others were for colon cancer screening only. Twelve patients had procedures completed as inpatients for urgent reasons (ie, acute gastrointestinal bleeding). Table 2 shows the most common indications for colonoscopy.

The success rate for reaching the cecum was found to vary among physicians from 91 to $100 \%$. The average rate for reaching the cecum overall was $96.5 \%$ (193 of 200) as shown in Table 3. Of the cases in which the cecum was not reached, 2 of 7 $(29 \%)$ were the result of an obstructing colon cancer, whereas 4 of 7 (57\%) were caused by a tortuous colon, and 1 was secondary to an anastomosis stenosis.

The average time to reach the cecum per physician varied from 6.5 to 23.8 minutes and is shown in Table 4 . The overall average time to reach the cecum was 15.9 minutes. The physician with the most experience had the shortest average time to the cecum, whereas the physician with the least experience had the longest. The overall average time for completion of the procedure was 34.4 minutes, including biopsies and polypectomies.

Table 3. Rate to Reach the Cecum

\begin{tabular}{lccc}
\hline Physician & $\begin{array}{c}\text { Number of } \\
\text { Colonoscopies }\end{array}$ & $\begin{array}{c}\text { Times Cecum } \\
\text { Reached }\end{array}$ & Percentage \\
\hline A & 23 & 21 & 91 \\
B & 45 & 43 & 96 \\
C & 24 & 24 & 100 \\
D & 108 & 105 & 97 \\
Total & 200 & 193 & 96.5 \\
\hline
\end{tabular}

Table 4. Average Time to Cecum and Procedure Completion by Physician

\begin{tabular}{lcc}
\hline Physician & $\begin{array}{c}\text { Average Time } \\
\text { to Reach Cecum } \\
\text { (minutes) }\end{array}$ & $\begin{array}{c}\text { Average Time to } \\
\text { Complete Procedure } \\
\text { (minutes) }\end{array}$ \\
\hline A & 23.8 & 51.1 \\
B & 16.6 & 36.5 \\
C & 16.9 & 33.7 \\
D & 6.5 & 16.3 \\
Average & 15.9 & 34.4 \\
\hline
\end{tabular}

During the study, 45 of 200 (22.5\%) cases were found to have neoplastic polyps that were confirmed by pathological examination. Table 5 demonstrates the frequency of neoplastic polyps found based on the most frequent preprocedure indications. Five of 200 (2.5\%) patients had confirmed colon cancer. The most common preprocedure diagnosis, for patients subsequently found to have colon cancer, was hemoccult-positive stools [3 of $35(8.5 \%)]$. The 2 other patients with colon cancer had a preprocedure diagnosis of anemia or rectal bleeding.

Complications were considered to be adverse events that required intervention and occurred during the procedure or after, if related to the procedure. Complications included use of reversal agents with sedation, cardiorespiratory problems with sedation, bowel perforation, hospital admission, emergency department visits, and bleeding requiring transfusion that may have been related to the procedure. A review of the patients' charts 2 years after completion of the study was completed to look for any possible delayed complications related to the procedure or missed colon cancers. There was 1 case of sedation-related bradycardia that required a single dose of atropine. One patient was admitted to the hospital for abdominal pain for

Table 5. Frequency of Neoplastic Polyps Based on Most Common Procedure Indications

\begin{tabular}{lcc}
\hline Indication & $\begin{array}{c}\text { Number } \\
\text { of Cases (Total) }\end{array}$ & $\begin{array}{c}\text { Percentage } \\
\text { of Cases }\end{array}$ \\
\hline Stools positive for FOBT & $9(35)$ & 26 \\
Hx of polyps & $13(49)$ & 27 \\
FHx of colon cancer & $8(44)$ & 18 \\
Rectal bleeding & $11(52)$ & 21 \\
\hline
\end{tabular}

Hx, history; FHx, family history; FOBT, fecal occult blood testing. 
Table 6. Review of Reported Rates of Reaching the Cecum More Than $90 \%$ of the Time

\begin{tabular}{|c|c|c|c|}
\hline Author & Year & $\mathrm{n}$ & $\begin{array}{l}\text { Rate to } \\
\text { Cecum } \\
\text { (\%) }\end{array}$ \\
\hline Marshall et $\mathrm{al}^{4}$ & 1993 & 418 & 96 \\
\hline Church $^{15}$ & 1994 & 2,907 & 93.6 \\
\hline Marshall and Barthel ${ }^{5}$ & 1995 & 423 & 93.4 \\
\hline Hopper et $\mathrm{al}^{12}$ & 1996 & 713 & 93 \\
\hline Chak et $\mathrm{al}^{1}$ & 1996 & 315 & 94.3 \\
\hline Pierzchajlo et $\mathrm{al}^{11}$ & 1997 & 751 & 91.5 \\
\hline Wexner et $\mathrm{al}^{16}$ & 1998 & 2,069 & 96.5 \\
\hline Tassios et $\mathrm{al}^{17}$ & 1999 & 430 & 91 \\
\hline Kim et $\mathrm{al}^{21}$ & 2000 & 909 & 96.4 \\
\hline Wexner et $\mathrm{al}^{18}$ & 2001 & 13,580 & 92 \\
\hline Anderson et $\mathrm{al}^{22}$ & 2001 & 755 & 91.6 \\
\hline Thomas-Gibson et $\mathrm{al}^{10}$ & 2002 & 505 & 93 \\
\hline Nelson et $\mathrm{al}^{6}$ & 2002 & 3,196 & 97 \\
\hline Current study & 2004 & 200 & 96.5 \\
\hline
\end{tabular}

observation overnight but required no intervention. One patient was admitted to the hospital after colonoscopy for observation for several hours because of other medical problems, the length of procedure, and the number of polyps removed. This patient required no intervention. One patient required placement of a rectal tube to relieve retained air within the colon, and symptoms resolved. There were no bowel perforations. No cases required sedation reversal medications.

\section{Discussion}

This study demonstrates that the quality of colonoscopy performed by adequately trained rural family physicians compares favorably with benchmarks reported in the literature. ${ }^{1-4}$ Although benchmarks have been poorly defined in the past, standards are now becoming more apparent. The literature suggests that the colonoscopist should be able to reach the cecum more than $90 \%$ of the time (Table 6). They should be able to perform a colonoscopy in a reasonable amount of time (Tables 7 and 8). They are required to find and diagnose all significant pathologic lesions. Finally, they must be able to complete the procedure with minimal risk of complications and patient discomfort.

The reported success rate for reaching the cecum has, in the past, varied from $57 \%$ to more than $95 \%$. $^{3}$ Our success rate to reach the cecum was $96.5 \%$. Our rate is similar to that of other pub-
Table 7. Review of Reported Time to Reach the Cecum

\begin{tabular}{lccc}
\hline Author & Year & $\mathrm{n}$ & $\begin{array}{c}\text { Mean Time } \\
\text { to Cecum } \\
\text { (minutes) }\end{array}$ \\
\hline Marshall $^{5}$ & 1995 & 34 & $9^{*}$ \\
Chak et al $^{1}$ & 1996 & 297 & $10.5^{*}$ \\
Kim et al $^{21}$ & 2000 & 909 & 6.9 \\
Anderson et al & 2001 & 755 & $5.6^{*}$ \\
Nelson et al & 2002 & 3196 & 10.5 \\
Current study & 2004 & 200 & 15.9 \\
\hline
\end{tabular}

* Median rather than mean.

lished studies shown in Table 6. The majority of studies reported in the last 10 years confirm that skilled endoscopists can reach the cecum more than $90 \%$ of the time. However, when considering endoscopists in training, the rate of successful cecal intubation is usually lower than $90 \% .^{1,3,5,8,14,17,19}$ The 4 physicians in our study all had cecal intubation rates greater than $90 \%$, suggesting that they meet the most widely studied standard in achieving technical competence in colonoscopy.

Confirmation of reaching the cecum can sometimes be a difficult task. All colonoscopies in our study were either videotaped or photographs were taken of cecal anatomy for confirmation, but these cases were not reviewed by outside staff. One study has considered the photograph documentation of cecal landmarks as confirmation of a complete colonoscopy. ${ }^{25}$ They found that it was difficult for reviewers to consistently agree on whether adequate visual documentation had been obtained. Since completion of our study, there have been no missed colon cancers reported in the study group.

The procedure time was divided into 2 primary measurements: (1) time to reach the cecum and (2) time to procedure completion. We found that our average time to the cecum was 15.9 minutes. However, there were cases in the study group in which

Table 8. Review of Reported Time to Complete Colonoscopy

\begin{tabular}{lrrr}
\hline Author & Year & $\mathrm{n}$ & $\begin{array}{c}\text { Mean Time to } \\
\text { Completion } \\
\text { (minutes) }\end{array}$ \\
\hline Wexner et al & 1998 & 1,023 & 34.7 \\
Wexner et al $^{18}$ & 2001 & 13,580 & 22.7 \\
Nelson et al $^{6}$ & 2002 & 3,196 & 30.6 \\
Current study & 2004 & 200 & 34.4 \\
\hline
\end{tabular}


polyps were removed before reaching the cecum; this would obviously lead to an increase in the time to reach the cecum. Further analysis was not performed on these cases.

Table 7 shows the time reported to reach the cecum in recent studies. It has been stated that a "reasonable standard" would be cecal intubation within 15 minutes or less. ${ }^{1}$ The 4 physicians in the current study showed a large amount of variation in their average time to reach the cecum (6.5 to 23.8 minutes). This seemed to be related to the number of previous procedures completed before beginning the study. A similar variation is seen when one compares the time to procedure completion among these same physicians (16.3 to 51.1 minutes). Table 8 shows recently reported studies that measured total procedure times for colonoscopy. The reported studies also show a considerable amount of variation in reported average times (22.7 to 34.7 minutes).

Various factors affect the amount of time required to reach the cecum and complete the colonoscopy procedure (including biopsies and polypectomies). Factors affecting these outcome measurements include physician experience, patient anatomy, quality of bowel preparation, pathology encountered, and reporting differences. For example, the study with the shortest reported time to reach the cecum subtracted the time consumed with polyp removal before reaching the cecum. ${ }^{22}$ At this time, more research is required to clarify these variables comparing colonoscopists and their procedure time.

Our study group included a heterogeneous collection of subjects. Patients were included regardless of their indication for colonoscopy. The indications ranged from asymptomatic screening to surveillance follow-up for polyps or prior colon cancer. Among this diverse patient population, we found a prevalence of neoplastic polyps of $22.5 \%$ and a prevalence of colon cancer of $2.5 \%$. These findings are consistent with what has been reported previously. ${ }^{24}$

The study group included a wide variety of patients based on age, indications (both diagnostic and therapeutic) and complicating medical conditions. The group also included both an inpatient (urgent) and outpatient (nonurgent) population. Some patients were believed to be too "high risk" and were referred to a larger medical center with subspecialist management. However, the number of patients who were not offered colonoscopy by the family physicians was not followed. Despite this, there were no serious complications in the study group. One adverse cardiopulmonary event ( 1 of $200,0.5 \%$ ) required intervention. There were no colon perforations. Our rate of procedurerelated morbidity was consistent with morbidity reported by others. ${ }^{6,7}$ The reported rate of mortality as a result of colonoscopy is greater than 1 in 5000 , and major morbidity is approximately $0.4 \%{ }^{6,7}$ The rate of colon perforation is reported to vary from 0.14 to $0.65 \%$ for diagnostic procedures and 0.15 to $3.0 \%$ for therapeutic colonoscopy (including polypectomy). ${ }^{23}$

The primary weakness of the study is the relatively small sample size; however, we continue to collect sample data prospectively and look forward to reporting this in the future. It is possible that patient complications that occurred after the day of the procedure could have been missed if the patient presented to another hospital for evaluation and treatment. However, this is unlikely because of the rural locality of the study hospital and the distance to the next largest medical facility. In addition, this patient study group is part of a rural primary care 5-clinic system with ongoing longitudinal follow-up that uses central data management.

\section{Conclusion}

As the number of indications for the use of colonoscopy increase, rural patients face mounting geographic and distance-related obstacles to obtaining the endoscopy services that they need. This study provides an appraisal of the quality of 200 consecutive colonoscopies provided by 4 rural family physicians with various degrees of experience for a heterogeneous group of patients. Outcomes were measured and compared with other published results. We found that well-trained rural family physicians could safely provide diagnostic and therapeutic colonoscopy for their patients.

Further research regarding quality measures for colonoscopy and setting "standards" regarding compliance with these measures is needed to allow objective comparison between colonoscopists. Research in this area will advance the quality of colonoscopy provided to all our patients, both urban and rural.

We thank Cheri Holthaus and Pat Forsman, of St. Mary's Hospital, who assisted greatly with data input and management. 


\section{References}

1. Chak A, Cooper GS, Blades EW, Canto M, Sivak MV Jr. Prospective assessment of colonoscopic intubation skills in trainees. Gastrointest Endosc 1996; 44:54-7.

2. Quality and outcomes assessment in gastrointestinal endoscopy. American Society for Gastrointestinal Endoscopy. Gastrointest Endosc 2000;52:827-30.

3. Bond JH, Frakes JT. Who should perform colonoscopy? How much training is needed? Gastrointest Endosc 1999;49:657-9.

4. Marshall JB, Barthel JS. The frequency of total colonoscopy and terminal ileal intubation in the 1990s. Gastrointest Endosc 1993;39:518-20.

5. Marshall JB. Technical proficiency of trainees performing colonoscopy: a learning curve. Gastrointest Endosc 1995;42:287-91.

6. Nelson DB, McQuaid KR, Bond JH, Lieberman DA, Weiss DG, Johnston TK. Procedural success and complications of large-scale screening colonoscopy. Gastrointest Endosc 2002;55:307-14.

7. Dafnis G, Ekbom A, Pahlman L, Blomqvist P. Complications of diagnostic and therapeutic colonoscopy within a defined population in Sweden. Gastrointest Endosc 2001;54:302-9.

8. Harper M, Pope JB, Mayeaux EJ, Davis TJ, Myers A, Lirette A. Colonoscopy experience at a family practice residency: a comparison to a gastroenterology and general surgery services. Fam Med 1997; 29:575-9.

9. Worthington DV. AAFP position paper. Colonoscopy: procedural skills. Am Fam Physician 2000;62: 1177-82.

10. Thomas-Gibson S, Thapar C, Shah SG, Saunders BP. Colonoscopy at a combined district general hospital and specialist endoscopy unit: lessons from 505 consecutive examinations. J R Soc Med 2002;95: 194-7.

11. Pierzchajlo RP, Ackermann RJ, Vogel RL. Colonoscopy performed by a family physician. A case series of 751 procedures. J Fam Pract 1997;44:473-80.

12. Hopper W, Kyker KA, Rodney WM. Colonoscopy by a family physician: a 9 year experience of 1048 procedures. J Fam Pract 1996;43:561-6.
13. Carr KW, Worthington JM, Rodney WM, Gentry S, Sellers A, Sizemore J. Advancing from flexible sigmoidoscopy to colonoscopy in rural family practice. Tenn Med 1998;91:21-6.

14. Cass OW, Freeman ML, Peine CJ, Zera RT, Onstad GR. Objective evaluation of endoscopy skills during training. Ann Intern Med 1993;118:40-4.

15. Church JM. Complete colonoscopy: how often? And if not, why not? Am J Gastroenterology 1994;89: 556-60.

16. Wexner SD, Forde KA, Sellers G, Geron N, Lopes A, Weiss EG, et al. How well can surgeons perform colonoscopy? Surg Endosc 1998;12:1410-4.

17. Tassios PS, Lada SD, Grammenos I, Demertzis K, Raptis SA. Acquisition of competence in colonoscopy: the learning curve of trainees. Endoscopy 1999;31:702-6.

18. Wexner SD, Garbus JE, Singh JJ. A prospective analysis of 13,580 colonoscopies. Reevaluation of credentialing guidelines. Surg Endosc 2001;15:25161.

19. Mitchell RM, McCallion K, Gardiner KR, Watson RG, Collins JS. Successful colonoscopy; completion rates and reasons for incompletion. Ulster Med J 2002;71:34-7.

20. Cotton PB, Connor P, McGee D, et al. Colonoscopy: practice variation among 69 hospital based endoscopists. Gastrointest Endosc 2003;57:352-7.

21. Kim WH, Young JC, Park JY, Min PK, Kang JK, Park IS. Factors affecting insertion time and patient discomfort during colonoscopy. Gastrointest Endosc 2000;52:600-5.

22. Anderson JC, Messina CR, Cohn W, et al. Factors predictive of a difficult colonoscopy. Gastrointest Endosc 2001;54:558-62.

23. Putcha RV, Burdick JS. Management of iatrogenic perforation. Gastroenterol Clin North Am 2003;32: 1289-309.

24. Rex DK. Colonoscopy: a review of its yield for cancers and adenomas by indication. Am J Gastro 1995; 90:353-63.

25. Marshall JB, Brown DN. Photodocumentation of total colonoscopy: how successful are endoscopists? Do reviewers agree? Gastroinstest Endosc 1996;44: 243-8. 